\title{
Internet or internet: The Use of Proper Nouns
}

\author{
Sean J. Kullman, MA
}

Proper nouns are particular nouns that identify a unique person, place, thing, or idea, and they are generally easy to identify. But the age of computer technology has introduced new sets of words that seem so important yet lack the true distinction of proper noun, and I too have fallen prey to the technological times; cringing as the word internet usurps its common place in the world of nouns and bestows upon itself a capital $I$.

The internet is a shortening of the word inter and network. In 1986, the U.S. Department of Defense used the word internet to describe "the linked computer networks of the U.S. Defense Department" [1]. As institutions developed their own internet systems, the word intranet emerged as a way to differentiate the internal system from the one and only internet. Yet, Internet justifiers and internet detractors have voiced their concerns.

Justifiers of the capital $I$ argue that the Internet is a unique thing, and they encourage users to capitalize the $I$ when referring to the Internet and a lowercase $i$ when speaking of an internet system. Detractors cite other common nouns that have not reached proper nouns status and argue that the internet has not earned the place of proper noun. Some publications (the London Times and others) have decided to use a lower case $i$, while other publications keep the capital $I$.

The argument hinges on usage. Internet detractors and internet justifiers voice valuable opinions about the use of common and proper nouns. Although the editors of the Journal of Medical Toxicology have never established a formal policy on the use of the word internet, it defers to general rules of grammar when identifying common and proper nouns. I tend to argue that the internet has not earned the same right as the Theory of Relativity or surpassed the common rights of the universe because the internet loosely refers to a "vast computer network linking smaller computers worldwide" [2]. The internet shares the same conceptual definition as the one and only universe, a common noun that links a whole.

1. Harper, Douglas. Online Etymology Dictionary. 2001. Accessed: 6 May 2007. http://www.etymonline.com/ index.php?search=internet\&searchmode=none

2. Dictionary.com. Accessed 2007. http://dictionary. reference.com/browse/internet 